\title{
A ludicidade como instrumento de discussão de temas identitários e culturais na literatura infantil - uma análise de Beto, o carneiro, de Ana Maria Machado, e $O$ voo do Golfinho, de Ondjaki
}

Ludic aesthetics as a gateway to identitary and cultural themes in children's literature - an analysis of Beto, o carneiro, by Ana Maria Machado, and $\mathrm{O}$ voo do Golfinho, by Ondjaki Taís Xavier CARVALHO* Indiana University Bloomington (IUB) Luciana NAMORATO** Indiana University Bloomington (IUB)

RESUMO: A literatura infantil é vista por muitos como um ramo menor da literatura, não atraindo muitos estudiosos por não ser identificada como detentora de temas complexos que possam ser aprofundados. No entanto, um olhar mais atento percebe que, na verdade, a literatura infantil não só lida com tópicos normalmente considerados "adultos", como também assume a tarefa de torná-los inteligíveis para crianças. Assim, o presente artigo se dedica a analisar duas obras infantis - Beto, o carneiro, da escritora brasileira Ana Maria Machado, e $O$ voo do Golfinho, do angolano Ondjaki - a fim de verificar de que forma questões de identidade e pluralização cultural podem ser percebidas em meio ao lúdico em narrativas infantis.

PALAVRAS-CHAVE: Literatura infantil. Temas lúdicos. Identidade. Diversidade cultural.

ABSTRACT: Children's literature is seen by many as a less important branch of literature and, as it is not normally associated with complex themes that can be examined in depth, it does not attract many scholars. However, a more attentive look reveals that, in fact, not only does children's literature deal with topics normally considered "adult", but it also takes on the task of making them intelligible to children. Hence, this essay analyzes two children's books - Beto, $o$ carneiro, by the Brazilian writer Ana Maria Machado, and $O$ voo do Golfinho, by the Angolan Ondjaki - and investigates how questions of identity and cultural pluralization can be perceived amidst the ludic issues in children's narratives.

KEYWORDS: Children's literature. Ludic themes. Identity. Cultural diversity.

\footnotetext{
* Mestranda em Literatura Luso-Brasileira do Departamento de Espanhol e Português em Indiana University Bloomington, Indiana. E-mail: tmxavier@indiana.edu

** Professora Associada do Departamento de Espanhol e Português em Indiana University Bloomington e Diretora do Programa de Português da mesma instituição. Doutora em Literatura Luso-Brasileira pela University of North Carolina at Chapel Hill. E-mail: lnamorat@indiana.edu
} 


\section{Introdução}

No contexto da contemporaneidade, novas realidades e necessidades humanas, especialmente aquelas derivadas de guerras mundiais no século $\mathrm{XX}$, deram origem a invenções inovadoras que alteraram drasticamente o dia-a-dia das pessoas. Os modernos e mais avançados meios de transporte, a internet e suas consequentes redes sociais, por exemplo, foram elementos responsáveis por intensificar o processo de globalização dentro do cenário mundial, promovendo ainda mais contato entre povos e culturas distintos e alterando noções de identidades pessoais e nacionais. Além disso, também é importante considerar que, antes dos citados eventos, os contornos que definiam as diferentes nações já tinham começado a ser borrados pelos processos de colonização, que mesclaram culturas e introduziram novos costumes tanto ao Novo quanto ao Velho Mundo. Assim, com tantas modificações ocorrendo ao redor do globo, não é de se surpreender que o conceito de identidade tenha passado por uma reforma denominada por alguns de "crise de identidade" (HALL, 1996, p. 596).

No ensaio "The Question of Cultural Identity”, Stuart Hall aborda a questão da modificação da noção de identidade em indivíduos pertencentes a sociedades pósmodernas, isto é, das décadas finais do século $\mathrm{XX}$, que entram em contato direto com outras vivências. Segundo Hall, devido a uma "pluralidade de centros" emanantes de cultura, as sociedades pós-modernas passam por uma mudança estrutural, sendo descentralizadas e fragmentadas e dando lugar a novas percepções de integração. Com isso, a própria noção identitária nacional fica turva, pois se torna difícil definir elementos culturais que pertençam somente a uma nação e, portanto, identifiquem-na.

Sobre a construção identitária nacional, Hall defende que os cidadãos não nascem com identidades nacionais já formadas, mas que estas são geradas e transformadas de acordo com as representações que o rodeiam. Segundo o autor, por exemplo, "We only know what it is to be 'English' because of the way 'Englishness' has come to be represented, as a set of meanings, by English national culture" (HALL, 1996, p. 612). Isso mostra como a visão existente de uma população de um determinado território pode ser flexível, pois são as representações culturais, não necessariamente permanentes, que a moldam. Logo, é possível perceber a importância que as disseminações culturais por meios artísticos ou populacionais (através das migrações) têm para a construção de uma noção do nacional, e que esta noção está sempre 
movimento. Nenhuma nação tem sua cultura congelada. Assim, ela está sempre apta a absorver novos conceitos e pensamentos (o que, no mundo pós-moderno, acontece a todo o momento).

Uma vez que é sabido que uma identidade nacional pode ser alterada com o tempo e com o contato com outras culturas, torna-se necessário buscar o que, dentro dessa noção identitária, permanece, e o que pode influenciá-la; em outras palavras, a construção de uma identidade nacional está relacionada às culturas que ela já absorveu e a outras que ainda podem penetrá-la. Nesse ponto, a literatura, bem como outras formas artísticas, se torna fundamental. Além de difundirem, em maior ou menor escala, a cultura nacional do território onde foram escritos e, consequentemente, contribuírem para a absorção dessa cultura por outras nações, os registros de um povo são representativos das culturas já incorporadas ao seu sistema. Como exemplo, é possível citar os autores brasileiros Machado de Assis, Mário de Andrade e Guimarães Rosa. Todos eles escreveram livros que, lidos dentro e fora do Brasil, foram responsáveis por contribuir para construir a noção de identidade nacional brasileira, pois explicitaram, seja por meio da linguagem, seja por meio do conteúdo, a constituição da nação e a presença de outras culturas dentro dela. ${ }^{1}$ Além disso, em movimento oposto, também há a difusão de cultura de outros países que acabam penetrando no território brasileiro e se incorporando a elementos do Brasil. Um exemplo é a arte musical de origem estrangeira que entra em contato com artistas brasileiros e se mistura à cultura local. Sobre isso, em entrevista, a autora Ana Maria Machado aponta que

O Chico [Buarque] trouxe coisas da Itália... Se não a gente não tinha proximidade... Então a gente teve uma proximidade com a música italiana por aí. Essa... O reggae que "tava" começando a chegar em Londres e que depois o [Gilberto] Gil trouxe também... Eu acho que essa abolição de fronteiras foi muito bonita. Foi uma coisa positiva. (MACHADO, 2014, 17 '12',-17'50',)

\footnotetext{
${ }^{1}$ Aqui me refiro especificamente à formação da sociedade brasileira - também composta por negros - e aos costumes de base europeia adotados pela população, que Machado de Assis revelou em seus contos e romances. Além disso, também faço alusão aos vários componentes culturais de origem indígena e africana presentes em Macunaíma (1928), de Mário de Andrade, e aos personagens mestiços de Grande sertão: veredas (1956), de Guimarães Rosa, cujas habilidades de se orientar pela natureza remetem ao povo indígena (ver publicação de Liana Depieri Amorim sobre o assunto). Também se pode notar a linguagem inovadora usada por Guimarães Rosa, que, ao criar alguns dos neologismos de seus textos, indica uma conexão com outras línguas influenciadoras do português, como em "Sagarana" (de Sagarana, 1946), em que o autor utiliza a palavra tupi "rana"; em "taurophtongo" (de Ave, palavra, 1970), em que há uso de "táuros" e "phtoggos", ambas palavras gregas; e em "velvo" (também de Ave, palavra), em que o escritor remete à palavra "velvet" do inglês.
} 
Já na literatura infantil, muito também se pode encontrar a respeito de identidade pessoal e nacional e dos elementos formadores da cultura brasileira, ainda que os tópicos sejam apresentados de forma diferente, de forma mais lúdica e didática. De fato, os temas abordados pela literatura infantil, quando analisados mais profundamente, surpreendem pela complexidade. Além de se permitirem tratar de questões políticas dos países com os quais os autores têm familiaridade, as obras escritas para o público jovem também se aproximam, sem hesitação, de assuntos mais abstratos e teóricos. Particularmente nas produções do angolano Ondjaki e da brasileira Ana Maria Machado é possível perceber como essas questões são abordadas. Como a própria escritora afirma em uma entrevista concedida a Glauco Ortolano, "Many do not understand that achieving simplicity without being simplistic is the greatest challenge for a writer of children's books" (MACHADO, 2002, p. 111). ${ }^{2}$ Logo, a autora revela as relações que cria, mesmo quando a história contém elementos de fantasia, entre suas obras infantis e a realidade, incluindo discussões sócio-históricas contemporâneas. Assim, Machado, fazendo uso da ludicidade, introduz tópicos comumente considerados adultos aos seus leitores jovens, expandindo seus horizontes e, consequentemente, preparando-os para um desenvolvimento pessoal e social. Ondjaki, assim como a autora brasileira, também faz uso da ludicidade para lidar com temas "adultos" em suas publicações destinadas ao público jovem. A diferença está no fato de que Ondjaki utiliza o contexto histórico de seu próprio país ao escrever e, entre outros tópicos, trata da marca deixada pelo colonizador na vida angolana, assim como do momento pós-independência - em que a população angolana buscava (e ainda busca) se estabelecer em meio a tantas heranças culturais.

\section{Beto, o carneiro}

Em Beto, o carneiro (1993), Ana Maria Machado apresenta a história de um carneiro - Bebeto - que se cansa de receber ordens de seu patrão sobre como deve se portar e manter o pelo e, por isso, decide fugir e tomar a forma de uma nuvem. No entanto, ele logo aprende que, mesmo como nuvem, não alcançará sua liberdade, pois estará sujeito às vontades do vento. Logo, resolve adotar a vida de espuma do mar.

\footnotetext{
2 "Muitos não compreendem que alcançar a simplicidade sem ser simplista é o maior desafio de um escritor de livros infantis". (Tradução nossa)
} 
Novamente, contudo, ele percebe que não poderá tomar suas próprias decisões, uma vez que se torna submisso aos comandos da onda. Então, ouvindo o choro de uma carneirinha negra solitária, ele decide voltar a ser carneiro e viver ao seu lado, cantando e viajando. Assim, os dois animais vivem “muito felizes por serem só carneirinhos" (MACHADO, 1993, p. 23) e assumem o estilo que querem, usando roupas coloridas que não permitem que se distinga "se eles eram brancos ou pretos" (MACHADO, 1993, p. 23). A obra, que a princípio parece puramente fantasiosa, então, termina por apresentar elementos mais complexos, e abordar tanto a questão de definição de identidade e raça, como noções políticas relacionadas à obediência civil.

Logo no início da história de Bebeto, o leitor é apresentado ao sentimento de inconformidade que envolve o personagem. A primeira frase já define Bebeto como "um carneirinho cansado de carneirice" (MACHADO, 1993, p. 5). Assim, a publicação, ainda que lúdica, problematiza definições pré-estabelecidas de comportamentos, abrindo espaço para individualizações. Tal abordagem não parece estranha a Machado, uma vez que a autora participou ativamente da luta contra o período da ditadura militar brasileira, defendendo a liberdade de expressão e a atuação política do povo. Na história infantil ela afirma os mesmos ideais pelos quais prega em sua vida pessoal e política. A diferença é que em Beto, o carneiro, a linguagem e o contexto se tornam mais simples. Como a própria escritora pontua em entrevista,

it is hard to rid oneself of the stigma of being a writer of "simple" things, because many just cannot see that distinction between writing about things that are born simple, and writing about complex issues made simple enough so that a child can grasp the underlying principles. The creation of that essence is what separates a good writer from a mediocre one in children's literature. (MACHADO, 2002, p. 111)

Assim, percebe-se que a história do carneiro Bebeto se liga sim a questões "adultas" reais, podendo-se dizer que não deixa de ser complexa por ser destinada ao público infantil, mas, antes, torna-se "simplificadamente complexa", pois passa por um processo de simplificação do contexto.

\footnotetext{
3 "É difícil livrar alguém do estigma de ser um escritor de coisas 'simples' porque muitos não conseguem ver a distinção entre escrever sobre coisas naturalmente simples e escrever sobre questões complexas que são transformadas em simples o bastante para que uma criança possa apanhar os princípios subjacentes. A criação dessa essência é o que separa um bom escritor de um medíocre na literatura infantil". (Tradução nossa)
} 
A existência de tal relacionamento entre a produção voltada ao mundo infantil e a realidade adulta é ratificada, ainda, pela continuação da história. Nela, Bebeto segue buscando uma identidade na qual se sinta confortável (nuvem e espuma do mar) e onde possa agir da maneira que achar melhor, mas não a encontra por sempre ter de se submeter às vontades de um ser mais poderoso. Dessa forma, a noção de identidade apresentada por Machado através de seu personagem entra em consonância com aquela apresentada por Sandra Pesavento, no artigo "A cor da alma: ambivalências e ambiguidades da identidade nacional". Segundo a autora, "A identidade, como representação social, formula uma maneira de ser que é inventada ou importada, mas é assumida e consentida" (PESAVENTO, 2000, p. 17). Assim, quando Bebeto se recusa a assumir identidades nas quais não se reconhece, Machado adiciona a noção de liberdade dentro do conceito de identidade explorado. Novamente, então, tem-se a relação entre a vida pessoal da autora e sua publicação. Torna-se claro para o leitor que Bebeto, além de desprezar noções pré-estabelecidas de comportamentos, ou seja, os estereótipos, também preza pelo livre-arbítrio, que fora tão enfatizado pela escritora no período ditatorial brasileiro. A recusa de Bebeto de desistir de sua individualidade, de ser calado (“- Não senhor, vamos para o mar. E nada de reclamar” (MACHADO, 1993, p. 10)), e portar-se como todos os demais pode ser entendida como uma crítica ao sistema governamental - destacando-se o regime ditatorial - e sociológico que insiste em cercear as liberdades individuais a fim de manter um controle maior sobre a população.

Por fim, Beto, o carneiro ainda se revela como obra "simplificadamente complexa" em sua cena final, em que Bebeto alcança a liberdade identitária que queria ao lado da carneirinha negra Memélia e volta à sua forma original de carneiro, percebendo que pode ser feliz sem ter de alterar sua forma original e assumir outras características. A princípio, quando os dois se conhecem, Memélia chora e se pergunta se não possui amigos por ser negra. Ora, a questão racial e a problematização de preconceitos de cor já podem ser identificadas facilmente nesse ponto da história. No entanto, Machado estende a abordagem da questão e a conduz até a última página do livro, dizendo que "Nem dava para ver se eles [Bebeto e Memélia] eram brancos ou pretos, porque estavam sempre com umas roupas muito coloridas, cheios de colares e enfeites" (MACHADO, 1993, p. 23). Dessa forma, a autora relaciona as noções de identidade de Bebeto com as de Memélia, passando a mensagem de que não importa 
quem o indivíduo seja ou como nasça; prender-se a estereótipos não é algo positivo, pois cada um é livre para portar-se da maneira que lhe convir - mesmo que uma figura de autoridade diga o contrário.

Dessa forma, por meio de sua publicação, Machado trata de questões de identidade e liberdade e de preconceitos. Ao contar a história de Bebeto - e sua insatisfação diante de quem era e da posição em que se encontrava - e de Memélia - e sua superação diante das barreiras sociais derivadas de sua cor -, a autora narra uma trama que pode ser interpretada como uma tradução de questões complexas para o mundo infantil. Assim, a criança leitora é apresentada a ideais defendidos pela escritora e, mesmo que não compreenda inteiramente o mundo que a cerca, apreende noções e percebe que um carneiro não precisa necessariamente se ater a "carneirices", e que um indivíduo singular, como é o caso do carneiro negro, não precisa ser excluído por ser diferente.

\section{O voo do Golfinho}

Ondjaki, assim como Ana Maria Machado, também inclui em seus livros temas relacionados à questão da cultura e da identidade nacional. Ao abordar-se o tema da escrita dentro do território angolano, contudo, não se pode ignorar o próprio uso que é feito da língua portuguesa. Afinal, essa funciona como uma evidência de como Portugal, enquanto país colonizador, modificou e marcou o modo de vida angolano, impondo os seus costumes sobre o país africano. Com a imposição do idioma estrangeiro, pode-se dizer que parte da identidade dos colonizados foi perdida, uma vez que a língua é responsável por carregar parte da bagagem cultural de um povo. Como afirma Mattoso Câmara Jr., "a língua é um fato de cultura como qualquer outro; integrase na cultura" (MATTOSO CÂMARA JR., 1955, p. 53). É possível, então, identificar a ocorrência de um processo de aculturação que atingiu muitos africanos que se viram despidos de uma identidade nacional, uma vez que seus costumes foram descartados e classificados como "selvagens" e "primitivos", conforme aponta Ondjaki em seu artigo "Let's Share the Dream: Stories for Children in Angola". Segundo ele, após a chegada dos portugueses, liderados por Diogo Cão, no Congo, em 1482, inibições e mesmo proibições de formas de expressão cultural foram estabelecidas a fim de ratificar as imposições políticas, religiosas e culturais infligidas pelo colonizador (ONDJAKI, 
2009, p. 46). Assim, a cultura tradicional africana foi generalizadamente sufocada, sendo suprimida para dar lugar aos supostamente "preferíveis", ou "corretos" costumes europeus. Em Pele negra, máscaras brancas, o filósofo martinicano Frantz Fanon trata deste assunto, assinalando que "O negro é um homem negro; isto quer dizer que, devido a uma série de aberrações afetivas, ele se estabeleceu no seio de um universo de onde será preciso retirá-lo. O problema é muito importante. Pretendemos, nada mais nada menos, liberar o homem de cor de si próprio" (FANON, 1952, p. 26). Desta forma, Fanon explicita o discurso propagado pelos europeus, que tinham como objetivo a justificação de sua superioridade e a validação de suas ações.

Dessa forma, uma parcela da população africana - incluindo angolanos - teve seus próprios hábitos nacionais sucateados, e chegou inclusive a lutar ao lado dos portugueses durante o período colonial e contra o seu próprio povo, na esperança de conquistar um reconhecimento junto ao colonizador. Uma vez que o colonizador português incutiu nos países colonizados a ideia de que a sua cultura era melhor e mais avançada, parte da população angolana se viu dominada pelos seus discursos, acreditando que, de fato, pertencer ao território português era mais conveniente e vantajoso do que ser uma nação livre subdesenvolvida. Todavia, é preciso ressaltar que também havia aqueles que se dedicavam a preservar suas tradições e costumes. De fato, a resistência era tão presente na África de colonização portuguesa, que, durante a ditadura salazarista portuguesa, que desejava manter o controle de Portugal sob a colônia africana, o governo "criou um aparato de controle que queria impedir o florescimento de uma identidade territorial, política e cultural" (PEREIRA; DUARTE, 2016, p. 286). Para isso, foi formada, pelo governo salazarista, a Casa dos Estudantes do Império (CEI), uma organização constituída, principalmente, de integrantes da elite africana que se mudavam para Portugal a fim de ter acesso a uma melhor educação formal. Inicialmente, a ideia da administração portuguesa era utilizar os intelectuais africanos para, através de sua voz nativa, difundir os ideais da metrópole em Portugal e nas colônias. Contudo, a formação da CEI resultou no efeito oposto, e o governo não conseguiu impedir que um sentimento de rebelião contra a dominação política e cultural europeia se espalhasse pelos países colonizados. Tal repudio pelas influências e costumes europeus - por vezes mais radical, por vezes mais moderado - ainda é, inclusive, praticado por alguns africanos até hoje. Estes buscam resgatar suas próprias 
tradições com o propósito de reafirmá-las e incorporá-las na construção da identidade nacional, substituindo a influência do antigo colonizador. Por isso, não é surpreendente encontrar nos livros de Ondjaki - e de outros escritores angolanos - vocabulário pertencente a línguas tradicionais africanas, como o umbundu e o kimbundu. Ao fazer uso de palavras não portuguesas, os autores angolanos procuram validar suas origens, rejeitando a influência colonizadora. No entanto, cabe lembrar que, embora o vocabulário tipicamente africano seja utilizado, as obras literárias angolanas ainda são escritas majoritariamente em português, marcando, assim, a presença histórica da metrópole.

É possível perceber, então, como o processo de colonização em Angola, iniciado no século XV e mantido durante pelo menos 500 anos, é capaz de ainda nos dias de hoje interferir em noções de identidade cultural do povo angolano. A tentativa de se realizar uma descolonização cultural é defendida por muitos desde, pelo menos, a década de 40 do século XX, época em que as guerrilhas pela independência começaram a ocorrer. Desde então a literatura angolana se envolveu na luta ideológica-cultural, buscando articular uma consciência nacional. Todavia, a rejeição completa da influência europeia se mostra impossível de ser executada, uma vez que determinados pontos culturais como a língua - já se encontram enraizados no território e já se tornaram parte da cultura angolana. Dentro desse contexto, como apontam Kleyton Pereira e Zuleide Duarte, a literatura assume um papel essencial no sentido de que os autores africanos se tornam os responsáveis por difundir as características de suas regiões e descrever seus modos de vida, admitindo a mescla cultural ou não:

\footnotetext{
As criações ficcionais possibilitam, ao leitor, enxergar a reação contra os paradigmas socioculturais herdados do colonialismo e a inserção de um discurso pós-colonial, que tem raízes profundas na realidade social, compondo um inventário da vida africana, de como ela se reflete na formação psíquica e emocional da sociedade. (PEREIRA; DUARTE, 2016, p. 290)
}

Assim, nota-se que as narrativas africanas apresentam uma agência que, além de histórica, é também sociocultural. Os autores não se limitam a contar histórias: eles também expressam ideologias acerca do mundo em que estão inseridos, transformando elementos aparentemente inocentes em símbolos culturais. Conforme foi assinalado, por exemplo, o uso de vocabulário advindo de tribos tradicionais africanas não é feito de maneira aleatória. A substituição, mesmo que breve, da língua portuguesa pelas línguas 
autóctones, presentes antes da chegada do colonizador português, reafirma o orgulho cultural do colonizado, que se nega a abandonar por completo suas raízes.

Tal dicotomia cultural pode ser encontrada na obra $O$ voo do Golfinho (2009), de Ondjaki. Assim como Ana Maria Machado faz em Beto, o carneiro, o autor angolano também cria um livro infantil baseado em um animal que deseja mudar de forma. Entretanto, enquanto na obra brasileira o carneirinho decide se tornar nuvem e espuma, em $O$ voo do Golfinho, o protagonista do autor angolano assume a identidade de outro animal. No livro, o leitor é apresentado à história do Golfinho que, apesar de ter crescido no mar e gostar de nadar, sente prazer em voar e exibe um bico semelhante ao de um pássaro. Com o passar da narrativa, ele assume cada vez mais suas características de ave, até que um dia, ao pular e encarar o seu reflexo na água, ele percebe o quanto de si se relaciona à vida de pássaro: seu bico, seu corpo e seu olhar. O mamífero, então, se transmuta em pássaro e se despede de seus amigos golfinhos, indo voar perto das nuvens, onde descobre outros animais que passaram pela mesma transformação: “Tu sempre foste pássaro?', / perguntei a um deles, muito colorido. / 'Não. Eu era uma serpente / mas sempre quis ser pássaro'. / Outro tinha sido canguru / outro tinha sido camaleão / outro tinha sido gato" (ONDJAKI, 2012, p. 15-17).

Considerando, então, os cruzamentos de espécies existentes na narrativa, e entendendo-os como referências à mistura de culturas, é possível relacionar os animais "híbridos" do livro aos africanos colonizados. Tal relação é possível quando se pensa nas heranças culturais existentes nos países, que, além de possuir suas próprias tradições, também se encontram influenciados por costumes e discursos europeus. Levando em consideração essa conexão, a natureza de golfinho estaria relacionada à cultura africana, às raízes do povo angolano, enquanto os aspectos de ave simbolizariam a influência do colonizador, que traz aquilo que é diferente. Logo, o leitor pode concluir que a tendência existente é a prevalência da cultura colonizadora sobre a colonizada. Esta linha interpretativa é ratificada pelo fato de animais de espécies diferentes também terem se tornado pássaros, o que mostra o quão amplamente esta espécie, ou seja, o colonizador europeu, se insere dentro de outras. A passagem em que o Golfinho percebe que o seu "olhar" parece o de um pássaro (ONDJAKI, 2012, p. 8) também apoia esta interpretação. $\mathrm{O}$ trecho é relevante porque remete ao discurso colonial de inferioridade africana propagado pelos colonizadores e que acabou sendo adotado por muitos dos 
próprios colonizados. A afirmativa do Golfinho de que ele mesmo reconhece em si muito de ave confirma a possibilidade de comparação do mamífero com o africano assimilado que assume, voluntária ou involuntariamente, muito da visão e do comportamento europeu. As sugestões de que as características do colonizador substituem de vez e por completo as características do colonizado são, entretanto, postas em questão com o desenvolvimento da narrativa. Em primeiro lugar, é preciso ressaltar que a conclusão de $O$ voo do Golfinho permanece em aberto; em segundo lugar, a dominação do colonizado pelo colonizador é posta em dúvida na última parte da obra, em que se torna claro que, apesar de gostar de ser um pássaro e até mesmo se sentir confortável como um, o Golfinho se recusa a abandonar suas raízes, aceitando e equilibrando, assim, seus dois lados: "Mas deixo-vos um segredo: / Hoje sou um pássaro / mas sempre que me apetecer / amanhã ou depois / um golfinho volto a ser" (ONDJAKI, 2012, p. 23).

Percebe-se, logo, como a questão pós-colonial, no que tange à cultura, está inserida em $O$ voo do Golfinho. Apesar da obra, diferentemente de outras do mesmo autor, não apresentar elementos da cultura africana propriamente dita, há o conflito entre duas naturezas, a de ser golfinho e a de ser pássaro, conflito este que pode ser interpretado como uma alegoria da história de Angola. Como explica Michelle Devides, "O pós-colonialismo aborda questões atuais de um país, de sua independência, mas com o seu arquivo ideológico carregado de uma influência exercida por uma potência europeia, desde o momento da invasão até os dias atuais" (DEVIDES, 2014, p. 291). Uma vez que o golfinho da história assume sua identidade híbrida, ele demonstra o nível de incorporação que já sofreu diante das duas naturezas. Ao fazer isso, ele também se alinha ao discurso de Homi Bhabha, que defende que os cruzamentos culturais

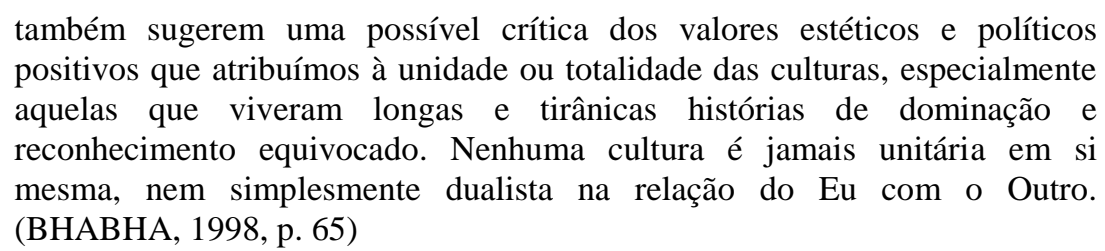

Assim, no contexto pós-colonial, a dicotomia relacionada ao Golfinho pode ser traduzida como o dilema enfrentado pelo indivíduo colonizado que se encontra entre a sua cultura tradicional - desprezada pelo colonizador - e a cultura do próprio colonizador, que, de imposta, se torna enraizada. 


\section{Considerações finais}

Os dois livros discutidos neste artigo - Beto, o carneiro e $O$ voo do Golfinho se relacionam com o contexto político vivenciado por seus autores: enquanto Ana Maria Machado testemunhou o regime ditatorial militar brasileiro, que foi responsável por seu exílio, Ondjaki presenciou parte da guerra civil angolana, além de todas as marcas deixadas no país pelo longo período de colonização portuguesa e de guerra colonial. Assim, ainda que não seja surpreendente identificar elementos em suas obras que remetem a questões políticas, identitárias e culturais das duas nações, é pertinente examinar como os dois autores traduzem questões nacionais de urgência em narrativas destinadas ao público infantil.

Em Beto, o carneiro, é significativo observar como Bebeto passa por diferentes formas, enquanto busca o seu lugar ideal em meio à sua "forma" original de carneiro. As diferentes formas que Bebeto assume podem ser entendidas como diferentes culturas nacionais, ou como variações de uma mesma cultura nacional brasileira. Sabendo que Ana Maria Machado escreve, como ela mesma afirma em entrevista, a fim de organizar o seu próprio caos interior (MACHADO, 2002, p. 113), pode-se concluir que a história de Bebeto se liga diretamente à sua vida pessoal e àquilo que ela é capaz de observar ao seu redor no ambiente em que vive. Beto, o carneiro foi publicado após o fim do período da ditadura militar no Brasil, mas ainda é possível notar como sua história funciona como eco daquilo que sua autora viveu - especialmente quando a ideia de identidade é levada em consideração. Não só aqueles que foram exilados, como a autora, mas também os demais cidadãos que permaneceram no país durante a violência e a censura que marcaram a ditadura militar brasileira viveram um período de flutuação de sua noção identitária. A propaganda e o nacionalismo imposto pelo governo, combinados com a realidade de opressão vivenciada por muitos brasileiros como uma realidade diária criaram um paradoxo identitário caracterizado por uma combinação ou alternância - entre identificação e repulsa dos indivíduos em relação ao nacional. Além disso, o próprio fim da ditadura causou uma grande transformação do país, confundindo assim ainda mais o conceito de identidade nacional. No entanto, conforme indica Benedict Anderson, nações são "comunidades imaginadas", mais do que territórios políticos (apud HALL, 2003, p. 26). Por essa razão, a nação brasileira 
terminou por se estabelecer novamente como uma comunidade integrada, após um período governamental tão turbulento, solidificando uma cultura e uma história nacionais que capazes de unir a população e reinstaurar um sentimento de orgulho. Isso também é o que fez Machado por meio de Bebeto, em Beto, o carneiro, obra que passa ao público infantil a ideia de que, apesar de idas e vindas, a identidade pessoal - e nacional - de cada indivíduo merece ser descoberta e valorizada. De forma semelhante, Ondjaki também mostra a importância de se identificar e aceitar a própria identidade, ainda que essa seja o resultado de uma transformação. Em $O$ voo do Golfinho, o autor não parece recusar as influências culturais estrangeiras que penetram as fronteiras de seu país; ele antes as aceita, desde que não apaguem suas próprias tradições - as quais ele também enfatiza na narrativa. A lição que fica é a de que Angola é um país social e culturalmente muito rico para ser vitimizado e/ou negligenciado. Por meio de sua obra, Ondjaki ensina que a identidade de nação inferior imposta ao continente africano é inteiramente falsa e urge ser modificada.

Ana Maria Machado e Ondjaki trazem discussões politizadas para dentro de suas obras infantis de uma forma lúdica, e talvez por isso, estas não causem grande estranhamento no público leitor a que suas obras se destinam. Os escritores inserem suas visões adultas em meio a elementos fantásticos e maravilhosos, fazendo, dessa forma, com que um tom de leveza e, consequentemente, esperança seja impresso em suas obras.

\section{REFERÊNCIAS}

AMORIM, L. D. A presença indígena na obra Grande sertão: veredas, de João

Guimarães Rosa. Nau Literária, Porto Alegre, v. 9, p. 1-13, 2013. Disponível em:

<www.seer.ufrgs.br/NauLiteraria/article/viewFile/43375/27873>. Acesso em: 17 set. 2017.

BHABHA, H. K. O local da cultura. Tradução de Myriam Ávila, Eliana Lourenço de Lima Reis e Gláucia Renate Gonçalves. Belo Horizonte: Editora UFMG, 1998.

DEVIDES, M. M. Evidências de discurso de resistência na literatura infantil de Ondjaki: uma análise da obra Ynari, a menina de cinco tranças. Revista de Humanidades, Tecnologia e Cultura, Bauru, v. 4, n. 1, p. 289-303, 2014. Disponível 
em: <www.fatecbauru.edu.br/ojs/index.php/rehutec/article/view/143>. Acesso em: 13 jul. 2017.

FANON, F. (1952) Pele negra, máscaras brancas. Tradução de Renato da Silveira. Salvador: Editora da Universidade Federal da Bahia, 2008.

HALL, S. Da diáspora: identidades e mediações culturais. Belo Horizonte: UFMG, 2003.

The Question of Cultural Identity. In: HALL, S.; HELD, D.; HUBERT, D.; THOMPSON, K. (Orgs.). Modernity: an Introduction to Modern Societies. Malden: Blackwell, 1996. p. 595-634.

MACHADO, A. M. Ana Maria Machado e suas memórias do exílio: exílio e canções. [2 out. 2014]. Brasília: TV Brasil. 26' 27', Entrevista concedida a Sérgio Britto. Disponível em: <www.tvbrasil.ebc.com.br/exilio-e-cancoes/episodio/ana-mariamachado-e-suas-memorias-do-exilio>. Acesso em: 25 maio 2017. Beto, o carneiro. São Paulo: Salamandra, 1993. An Interview with Ana Maria Machado. World Literature Today, Norman (Oklahoma), v. 76, n. 2, p. 109-113, 2002. Entrevista concedida a Glauco Ortolano. MATTOSO CÂMARA JR., J. Língua e cultura. Revista Letras, Paraná, v. 4, p. 51-59, 1955. Disponível em: <www.revistas.ufpr.br/letras/article/view/20046/13227>. Acesso em: 13 ago. 2017.

ONDJAKI. Let's Share the Dream: Stories for Children in Angola. Bookbird: A Journal of International Children's Literature, Baltimore, v. 47, n. 2, p. 46-52, 2009. O voo do Golfinho. São Paulo: Companhia das Letrinhas, 2012. PEREIRA, K.; DUARTE, Z. Diáspora, exílio e memória nas literaturas africanas em língua portuguesa. Miscelânea, Assis, v. 19, p. 283-302, 2016. Disponível em: <www.assis.unesp.br/Home/PosGraduacao/Letras/RevistaMiscelanea/v-19-art-17kleyton-pereira-e-zuleide-duarte.pdf>. Acesso em: 28 jun. 2017. PESAVENTO, S. J. A cor da alma: ambivalências e ambiguidades da identidade nacional. Caravelle, Toulouse, n. 75, p. 15-24, 2000. 